\title{
Prominent Role of the Spinal Central Pattern Generator in the Recovery of Locomotion after Partial Spinal Cord Injuries
}

\author{
Grégory Barrière, Hugues Leblond, Janyne Provencher, and Serge Rossignol \\ Multidisciplinary Team in Locomotor Rehabilitation of the Canadian Institutes of Health Research and Groupe de Recherche sur le Système Nerveux \\ Central, Canada Research Chair on the Spinal Cord, Department of Physiology, University of Montreal, Montreal, Quebec, Canada H3T 1J4
}

\begin{abstract}
The re-expression of hindlimb locomotion after complete spinal cord injuries (SCIs) is caused by the presence of a spinal central pattern generator (CPG) for locomotion. After partial SCI, however, the role of this spinal CPG in the recovery of hindlimb locomotion in the cat remains mostly unknown. In the present work, we devised a dual-lesion paradigm to determine its possible contribution after partial SCI. After a partial section of the left thoracic segment T10 or T11, cats gradually recovered voluntary quadrupedal locomotion. Then, a complete transection was performed two to three segments more caudally (T13-L1) several weeks after the first partial lesion. Cats that received intensive treadmill training after the partial lesion expressed bilateral hindlimb locomotion within hours of the complete lesion. Untrained cats however showed asymmetrical hindlimb locomotion with the limb on the side of the partial lesion walking well before the other hindlimb. Thus, the complete spinalization revealed that the spinal CPG underwent plastic changes after the partial lesions, which were shaped by locomotor training. Over time, with further treadmill training, the asymmetry disappeared and a bilateral locomotion was reinstated. Therefore, although remnant intact descending pathways must contribute to voluntary goal-oriented locomotion after partial SCI, the recovery and re-expression of the hindlimb locomotor pattern mostly results from intrinsic changes below the lesion in the CPG and afferent inputs.
\end{abstract}

Key words: spinal cord injury; locomotion; plasticity; central pattern generator; treadmill training; cat

\section{Introduction}

The general accepted model of locomotor control is tripartite. At the core is a spinal central pattern generator (CPG) for locomotion (Grillner, 1981), a genetically programmed neural network (Grillner, 1973) that can operate autonomously after all descending commands have been severed (Grillner and Zangger, 1979). The spinal CPG generates the detailed locomotor rhythm of the hindlimbs (HLs), characterized by alternation of flexor and extensor muscles of one hindlimb in opposite phase with the other limb. The importance of this CPG is made clear by the observation that after a complete spinal section at T13, kittens and adult cats recover hindlimb locomotion on a treadmill (Forssberg et al., 1980a,b; Barbeau and Rossignol, 1987; Lovely et al., 1990). The second control element are the sensory feedback generating phasic signals to the CPG allowing adaptation to real environments

\footnotetext{
Received Dec. 21, 2007; revised Feb. 18, 2008; accepted Feb. 20, 2008.

This work was supported by a Canada Research Chair on the Spinal Cord as well as individual and group grants from the Canadian Institute for Health Research (CIHR) to S.R. G.B. received a postdoctoral fellowship from the Multidisciplinary Team on Locomotor Rehabilitation of the CIHR (Regenerative Medicine and Nanomedicine, CIHR Strategic Initiative). We are very grateful to Alain Frigon for helpful discussion and careful reading of this manuscript and to Julien Cohen-Adad for anatomical MRI acquisition and processing. We also thank P. Drapeau and C. Gagner for their competent help with this work.

Correspondence should be addressed to Dr. Serge Rossignol, Centre de Recherche en Sciences Neurologiques, Pavillon Paul G. Desmarais, 2960 Chemin de la Tour, Université de Montréal, Montréal, Québec, Canada H3T 1J4. E-mail:Serge.Rossignol@umontreal.ca.

D0I:10.1523/JNEUROSC1.5692-07.2008

Copyright $\odot 2008$ Society for Neuroscience $\quad$ 0270-6474/08/283976-12\$15.00/0
}

made of uneven terrains and obstacles (Rossignol, 2006; Rossignol et al., 2006). Finally, descending pathways (third control element) from the telencephalon and the brainstem are essential in providing start-stop signals, steering, coordination, posture, anticipatory adjustments and also neurochemical drive to the cord (Rossignol, 1996). These three control mechanisms are in an exquisite balance so that compensatory adjustments can cope with most of the usual demands on the locomotor system.

After partial spinal cord injury (SCI), this optimal balance is perturbed because communication between the brain and the spinal CPG is altered (Barbeau and Rossignol, 1994). However, after bilateral dorsolateral or ventrolateral lesions, or lateral hemisections at low thoracic levels, cats can recover voluntary quadrupedal locomotion albeit with some deficits specific to each lesion (Kato et al., 1984; Gorska et al., 1993; Helgren and Goldberger, 1993; Jiang and Drew, 1996; Kuhtz-Buschbeck et al., 1996; Brustein and Rossignol, 1998; Rossignol et al., 1999). The recovery of locomotion after partial lesions may depend on multiple cooperative mechanisms that can be regrouped under the general heading of neuroplasticity (Wolpaw and Tennissen, 2001; Nudo, 2006; Rossignol, 2006). After partial SCI, the regeneration of damaged fibers and/or sprouting of undamaged fibers may contribute to recovery (Fouad et al., 2001; Raineteau and Schwab, 2001; Raineteau et al., 2002; Bareyre et al., 2004; Ballermann and Fouad, 2006). Plastic changes within descending pathways could suggest that inputs from the brain and brainstem 
supplant functions normally performed by the spinal locomotor CPG. Another likely scenario, however, is that the spinal CPG retains its function and that changes in descending commands aim at maintaining an optimal control of the spinal locomotor network. However, the role of the CPG in the recovery of locomotion after incomplete spinal cord lesion is mostly unknown.

To address this question, we devised a dual-lesion paradigm in the cat, consisting of an initial partial spinal lesion at T10-T11, a period of recovery, which was then followed by a complete spinal section at T13-L1. We hypothesized that changes within the spinal cord occurring during the recovery period after the initial partial lesion could be retained and revealed after the complete spinalization. In addition, we tested the potential role of locomotor treadmill training in the plastic reorganization of the CPG.

\section{Materials and Methods}

\section{Animal care}

The well being of the cats was always ensured. All procedures follow a protocol approved by the Ethics Committee at Université de Montréal, according to the Canadian Guide for the Care and Use of Experimental Animals. All animals were regularly checked and followed by a veterinarian. Cats were housed in large individual cages $(104 \times 76 \times 94 \mathrm{~cm})$ with food and water. After the lesions, foam mattresses were placed in the cages and cats were attended to a few times per day to clean the head connectors, express the bladder and clean the hindquarters when necessary.

\section{The dual-lesion paradigm}

Adult cats ( $n=5,1$ male, 4 females) were first selected for their ability to walk regularly for several minutes $(10-15 \mathrm{~min})$ on a motor-driven treadmill running at different speeds $(0.4-0.8 \mathrm{~m} / \mathrm{s})$. Thereafter, all cats were engaged in the dual-lesion paradigm.

Figure 1 illustrates the sequence of events of this dual-lesion paradigm. After recording sessions $(n=5-10)$ to obtain control electromyographic (EMG) and kinematic values for locomotion in the intact state, all cats underwent a partial spinal lesion targeting the left side of the spinal cord at the thoracic level (T10 or T11) (see Fig. $1 A, B$, green bar). A first group of cats (cats 1 and 2) were not systematically trained after the partial lesion, but only occasionally evaluated for brief periods of time on the treadmill and only during nonconsecutive days (cat 1: 5, 7, 12, 14, 16, and $19 \mathrm{~d}$; cat 2: 7 and $11 \mathrm{~d}$ ). These cats, in which the effect of a specific treadmill locomotor training was minimized, are referred to as untrained cats. A second group of cats, cats 3, 4 and 5, that are referred to as trained cats, received an intensive and specific treadmill locomotor training in this incomplete spinal state. The training regimen consisted of 20-30 min of quadrupedal locomotion on the treadmill 3-5 d per week. During a training session, the treadmill speed was progressively increased up to the maximal speed that the cats could readily follow for numerous consecutive steps. The maximal speed of quadrupedal locomotion was one of the parameters chosen to document the recovery process and establish the recovery plateau after the partial lesion in trained cats.

The second step in the dual-lesion paradigm consisted of a complete transection of the spinal cord two to three segments below the initial partial lesion (T13 or L1) (see Fig. $1 A, B$, red bar). The complete lesion of the spinal cord was done 26 and $55 \mathrm{~d}$ after partial lesion in untrained cats 1 and 2, respectively. In trained cats, the complete lesion was performed when the performance of the cats (the maximal treadmill speed at which the animal can walk for numerous successive steps) plateaued 95, 21, and $68 \mathrm{~d}$ after partial lesion in cats 3, 4, and 5, respectively. In all cats, spinal hindlimb locomotion was then evaluated early after the complete spinalization. This could be achieved as early as $24 \mathrm{~h}$ after the lesion in trained cats and respectively $48 \mathrm{~h}$ and $4 \mathrm{~d}$ after injury in cats 1 and 2. During spinal hindlimb locomotion, the forelimbs (FLs) were kept stationary on a platform fixed at $\sim 2 \mathrm{~cm}$ above the treadmill. After this complete spinal section, all five cats were regularly trained on the treadmill for about three to 4 weeks during which the recovery was documented.

Scratching activity of the hindlimbs was sometimes studied in cats 3 and 5 after the partial lesion. To do so, the left or right ear was gently tickled using a thin brush.

\section{Surgical procedure}

All surgeries were done under general anesthesia and aseptic conditions. Animal were first subcutaneously injected with an analgesic (Anafen, 2 $\mathrm{mg} / \mathrm{kg})$ and premedicated $(0.1 \mathrm{mg} / \mathrm{kg}$ atravet, $0.01 \mathrm{mg} / \mathrm{kg}$ glycopyrrolate, and $10 \mathrm{mg} / \mathrm{kg}$ ketamine; i.m. administration). Cats were then intubated and maintained through gaseous anesthesia (isoflurane $2 \%$ in a mixture of $\left.95 \% \mathrm{O}_{2} / 5 \% \mathrm{CO}_{2}\right)$. Heart rate and respiration were monitored throughout the surgery. Before the end of the surgery, an analgesic (buprenorphine $0.01 \mathrm{mg} / \mathrm{kg}$ ) was administered subcutaneously. Additionally, a patch of fentanyl $(25 \mu \mathrm{g} / \mathrm{h})$ was applied on the skin for $5 \mathrm{~d}$ to alleviate pain. At the end of the surgery, animals were placed in an incubator until they regained consciousness after surgery and housed in their spacious individual cages with food and water. As a prophylactic measure, an oral antibiotic (Cephatab or Apo-cephalex, $100 \mathrm{mg} / \mathrm{d}$ ) was given for $10 \mathrm{~d}$ after each surgery.

EMG implantation. Cats were chronically implanted under general anesthesia with intramuscular electrodes to record EMG activity from seven flexor and extensor hindlimb muscles on both sides. The implanted muscles were iliopsoas (Ip; hip flexor), gluteus medius (Glu; hip extensor), sartorius (Srt; hip flexor, knee extensor), semitendinosus (St; knee flexor and hip extensor), vastus lateralis (VL; knee extensor), gastrocnemius lateralis (GL) and medialis (GM; ankle extensors and knee flexors), and tibialis anterior (TA; ankle flexor). Electrodes were connected to two 15 pin-head connectors secured to the cranium using acrylic cement.

Spinal lesions. The general procedure for spinal lesions was similar to previous work (Brustein and Rossignol, 1998). During the first surgery, a low thoracic vertebra was exposed (T10, cat 3; T11, cats 1, 2, 4, and 5) and a small laminectomy was performed to approach the spinal cord dorsally. A small incision of the dura was first made and a local anesthetic (xylocaine, 2\%) was put first on the surface of the exposed spinal cord and then into the targeted segment to prevent axon discharges and brisk movements during the section. Partial lesions on the left side were achieved with a microknife under a microscope and an absorbable hemostat (Surgicel, oxidized regenerated cellulose) was used to fill the lesioned area so as to prevent axonal regrowth through the gap. The wound was then closed in anatomic layers. The same methodology was used for the complete transection of the spinal cord at T13 (cats 1-4) or L1 (cat 5).

After each section of the spinal cord in cats 3, 4, and 5, the lesions were first evaluated in magnetic resonance imaging (MRI) (see Fig. 1 A). Cats were anesthetized and placed in the scanner (isoflurane, 2\%) and breathed freely. MRI data were acquired on a Siemens trio system (3T) with an eight-channel spine coil. Radio-frequency transmission was performed using the body coil integrated into the magnet bore. Acquisition was performed on the thoracolumbar region (T6-L7) with the cat positioned feet-first supine. Anatomical scans were conducted with the following parameters: three-dimensional inversion recovery T1-weighted sequence; coronal orientation; $256 \times 256$ matrix; 112 slices; repetition time, $1800 \mathrm{~ms}$; echo time, $3.53 \mathrm{~ms}$; flip angle, $90^{\circ}$; voxel size, $0.75 \times$ $0.75 \times 0.75 \mathrm{~mm}^{3}$. Postmortem histological analysis $(40 \mu \mathrm{m}$ serial sections using cresyl violet) of the spinal cord in each cat was used for the evaluation of the lesion extents (see Fig. 1C).

\section{Recording procedures}

During episodes of locomotion, cats were recorded from the left side with a digital video and the data were stored on DVD support. For each session, six reflective markers were placed on the skin on bony landmarks at each joint of the left hindlimb so that joint angles [hip, knee, ankle and metatarsophalangeal (MTP) joints] and foot lifts/contacts could be reconstructed from the de-interlaced video images yielding 60 fields/s or a resolution of $16.6 \mathrm{~ms}$ between fields. A supplementary reflective marker was also sometimes placed on the tip of the toes of the right hindlimb to extract its step length during locomotion and reconstruct the position of the toe from the hip at lift and contact events (see Fig. 7, inset). Two additional markers glued on the treadmill were used for calibration (10 $\mathrm{cm})$. Kinematics were then reconstructed from the $\mathrm{x}-\mathrm{y}$ coordinates of 
A

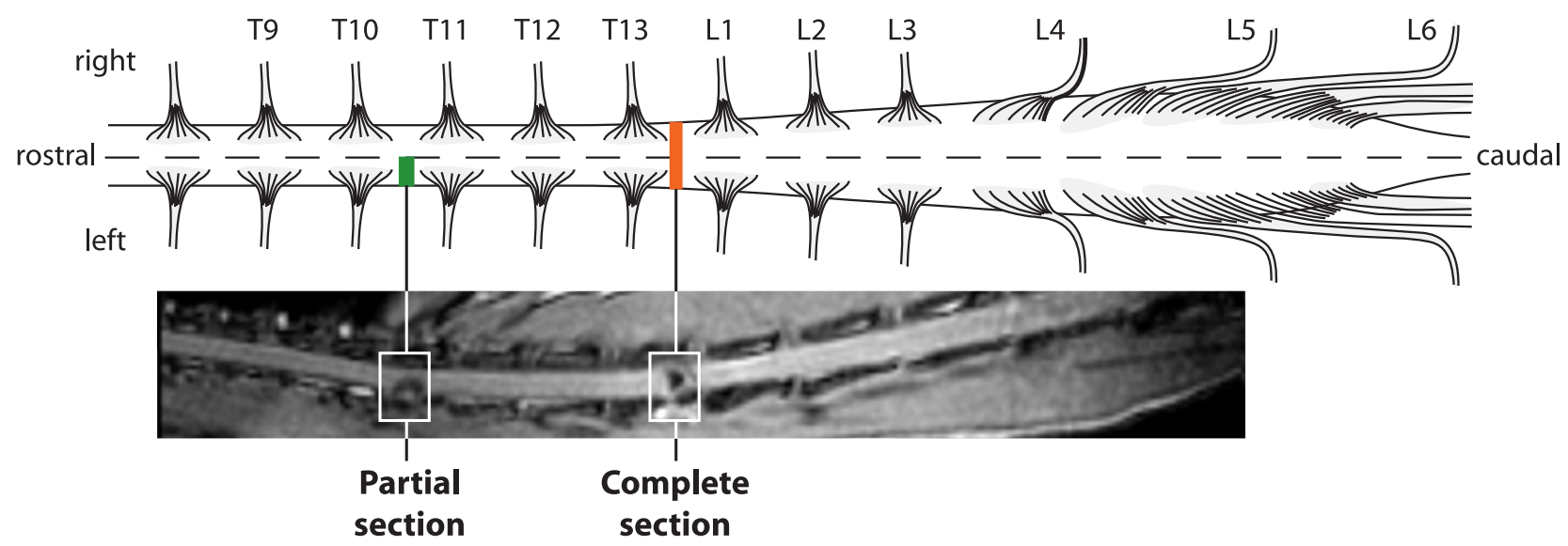

B

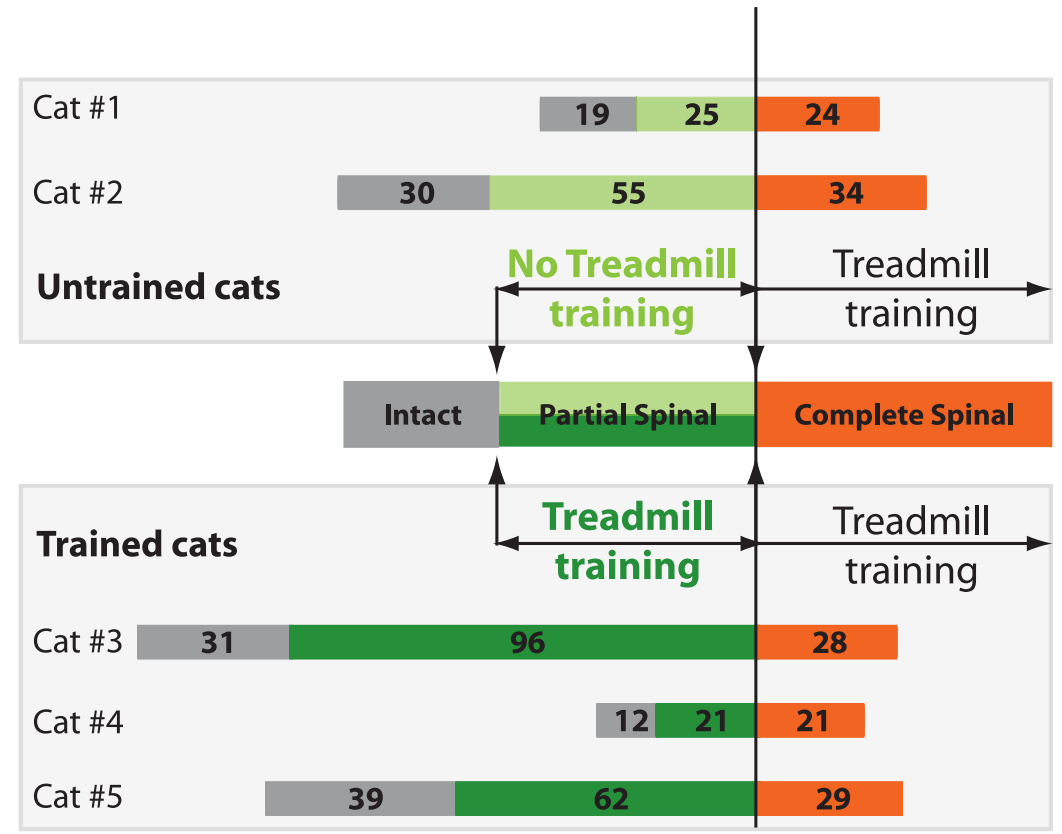

C

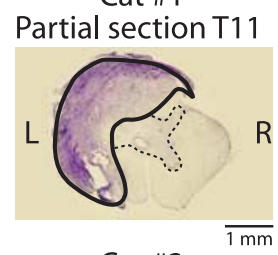

Cat \#3

Partial section T10

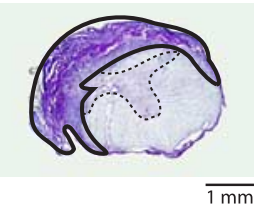

Cat \#5

Partial section T11

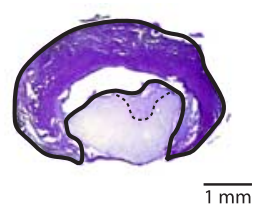

Cat \#2

Partial section T11

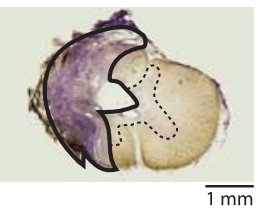

Cat \#4

Partial section T11

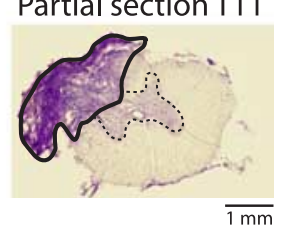

Figure 1. General description of the dual-lesion paradigm. A, Schematic drawing of a cat spinal cord and corresponding anatomical MRI view (coronal) extracted from cat 5 showing the levels of the incomplete (T10 -T11) and complete (T13-L1) sections. B, Sequence of events used in five cats aligned on the time of complete section. Cats were first documented in the intact state (gray) for several weeks after a partial thoracic section on the left side (green) and finally after a complete section (orange) of the spinal cord. Three cats (3,4, and 5) were intensively trained (dark green) on a treadmill after the partial spinal section for several weeks, whereas cats 1 and 2 were only evaluated (light green) early after the partial section and were not systematically trained. The number of days for each state is indicated in the corresponding horizontal bars for each cat. C, Histology of the partial lesion of the left thoracic segment at T10 -T11 in untrained (1 and 2) and trained (3, 4 , and 5) cats. The lesioned area is delimited by a continuous black line and the intact gray matter by a dotted line, the remainder corresponding to the intact white matter.

each marker using custom-made software allowing the calculation of the joint angular displacement and stick diagrams representation of the hindlimb for one or several consecutive steps. Kinematics and EMG recordings were synchronized using a SMPTE (Society of Motion Picture and Television Engineers) time code generator. The amplified (Neuralynx, Lynx-8 amplifiers) and filtered (bandwidth $100 \mathrm{~Hz}$ to $3 \mathrm{kHz}$ ) EMG signals were digitized at $1 \mathrm{kHz}$ (National Instruments, NI-6071E) and stored on a computer.

\section{Results}

\section{Extent of the lesions}

The dual-lesion paradigm was achieved in two steps. The first step consisted of an incomplete section of the spinal cord at the thoracic level T10 or T11. The second step was a complete transection of the spinal cord at T13 or L1. A schematic diagram and a representative anatomical MRI coronal view of a cat spinal cord (cat 5) illustrate the levels of the incomplete and complete lesions in Figure $1 A$. Postmortem histological examination of the spinal cord in the five cats further confirmed that the spinal section achieved in the first part of the paradigm was incomplete (Fig. $1 C$ ) and that the second transection was complete (data not shown). Photographs of the partial sections in all cats are shown in Figure 1C. Cats 1, 2 and 3 presented a similar partial section which mostly destroyed the left half of the spinal cord. In cat 1 , the left side was entirely destroyed except for the central gray matter and a small portion of the left medioventral quadrant. On the right side, the gracilis fasciculus and a small portion of the cuneatus fasciculus were also damaged. In cat 2, the lesion affected almost the entire left portion of the white and gray matters, the only tissue preserved being in the medioventral area; the right side remained intact. In cat 3, the lesion mostly destroyed the dorsal columns, and the greatest part of the dorsolateral quadrant and ventrolateral quadrant, sparing the left medioventral quad- 
A

Intact

$0.7 \mathrm{~m} / \mathrm{s}$
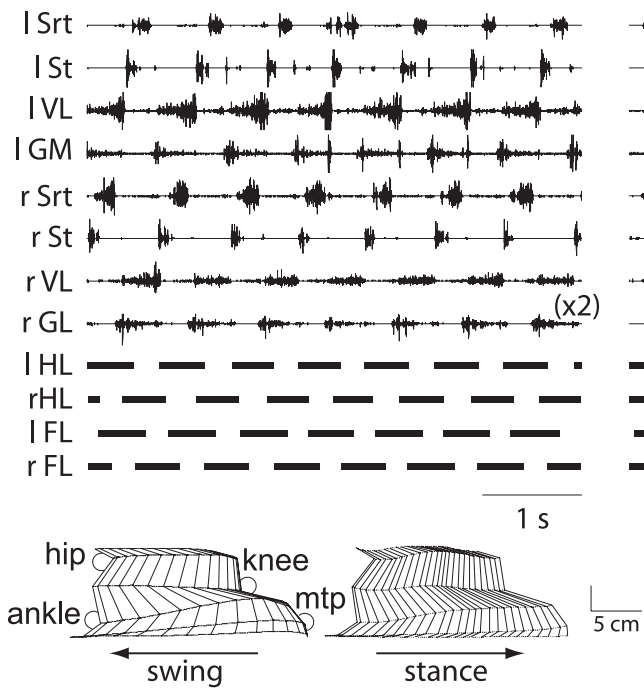

C
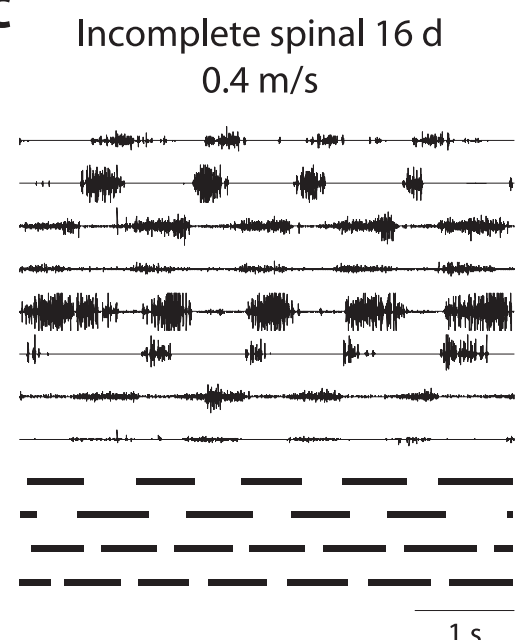

$1 \mathrm{~s}$
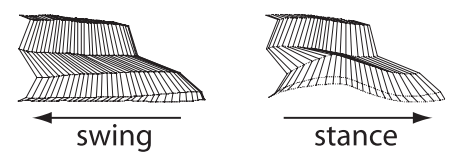

Figure 2. Left limb kinematics and bilateral EMG activity of a trained cat (5) walking on the treadmill in the intact state and at different epochs after the incomplete spinal cord lesion. $\boldsymbol{A}-\boldsymbol{D}$, EMG bursts of selected muscles in the left (I) and right ( $r$ ) hindlimbs (top). The four bottom traces show associated duty cycles of the stance phases for the HLs and FLs bilaterally. The bottom panels show a stick representation of a typical swing and stance phase of the left hindlimb reconstructed from video recordings.

\section{B \\ Incomplete spinal $3 \mathrm{~d}$ $0.4 \mathrm{~m} / \mathrm{s}$}

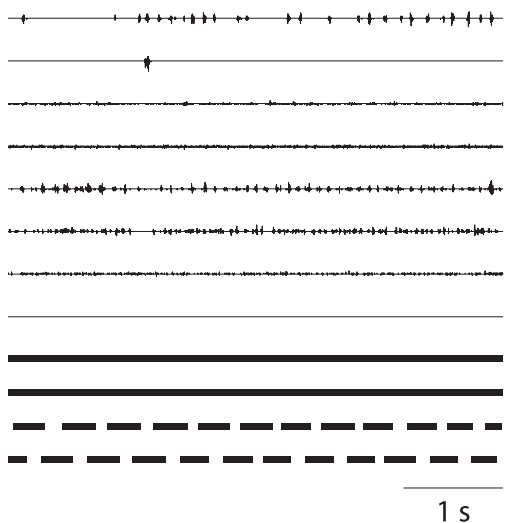

D
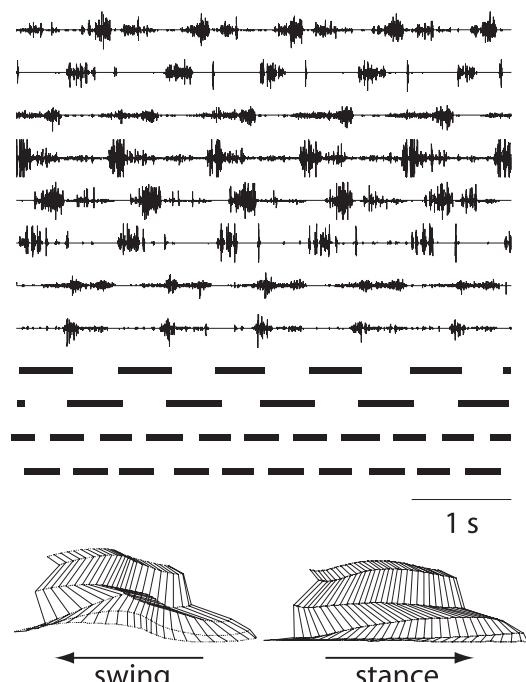

transiently abolished unilaterally or bilaterally during the first few days after the lesion. In cat 4 , with the smallest lesion of the left dorsal quadrant (Fig. 1C), only the left hindlimb was initially affected but tonus and locomotor movements rapidly recovered within 2-3 d (not illustrated). In contrast both cat 3 (intermediate lesion) and cat 5 (large lesion), showed an initial bilateral hindlimb paralysis. The early locomotor deficit on the treadmill in these cats is illustrated in Figure $2 B$ for cat 5 that presented the most extensive partial injury (Fig. 1C). At that time, the cat had to be weight-supported and no consistent EMG activity was recorded in both hindlimbs. As a result, both HLs passively dragged on the treadmill as shown by the continuous black bars below the electromyograms representing the period of foot contact with the treadmill. The stick representation of the left leg (bottom panel) reconstructed from the video recording also illustrates the lack of activity. It can be noted however that forelimb locomotion was not impaired by the lesion.

Despite different partial spinal damage, voluntary quadrupedal locomotion recovered in all trained cats. This was rapidly achieved in cats 3 and 4 because both cats could voluntarily step on the treadmill by 2 and $4 \mathrm{~d}$, respectively. In cat 5 , much more training was required and the first consistent episodes of locomotion at low treadmill speed $(0.4 \mathrm{~m} / \mathrm{s})$ with all four limbs were observed $16 \mathrm{~d}$ after injury (Fig. 2C). At that time, the experimenter gently held the tail in this cat to compensate for the poor lateral balance during locomotion, with care not to provide hindquarters support. An alternating bursting activity in flexor and extensor muscles similar to the one recorded at higher treadmill speed in the intact state (Fig. $2 \mathrm{~A}$ ) was observed bilaterally and both hindlimbs adequately stepped in strict alternation $(0.49 \pm 0.02, n=18)$. However, locomotor episodes consisted of no more than $\sim 10-12$ consecutive steps during which an incorrect dorsal placement of the toes at foot contact, most fre-

rant as well as most of the contralateral cord. Cat 4 presented the smallest partial lesion (about one-fourth) affecting the dorsal columns as well as the dorsal horn and the dorsolateral quadrant on the left side. The most dramatic partial section was observed in cat 5 . In this cat the whole spinal cord was damaged except a small portion of the ventral white and gray matters on the right side.

\section{Motor recovery in the incomplete spinal state}

Re-expression of quadrupedal locomotion

Trained cats. The primary consequence of the partial spinal section in all cats was a hindlimb flaccid paresis on the side of the lesion or on both sides depending on the extent of the damage. As a result, hindquarter support and locomotor movements were quently done behind the hip, was sometimes observed. In addition, the anteroposterior coupling was lost, the forelimbs cycle duration (768 $\pm 70 \mathrm{~ms}, n=24)$ being shorter than in the hindlimbs (1015 $\pm 149 \mathrm{~ms}, n=18)$ (Fig. 2C). Such a different locomotor period of the forelimbs and hindlimbs was also noted in cat 3. Overall, all three trained cats recovered relatively quickly, depending on the extent of the lesion, from the initial hindlimb flaccid paresis and regained the ability to step quadrupedally on the treadmill.

Over time, treadmill training gave rise to the recovery of high performance treadmill stepping. Figure $2 D$ emphasizes this aspect in cat 5 by the end of the treadmill training $62 \mathrm{~d}$ postlesion. At that time, the cat could voluntarily step as fast as $0.7 \mathrm{~m} / \mathrm{s}$ for 


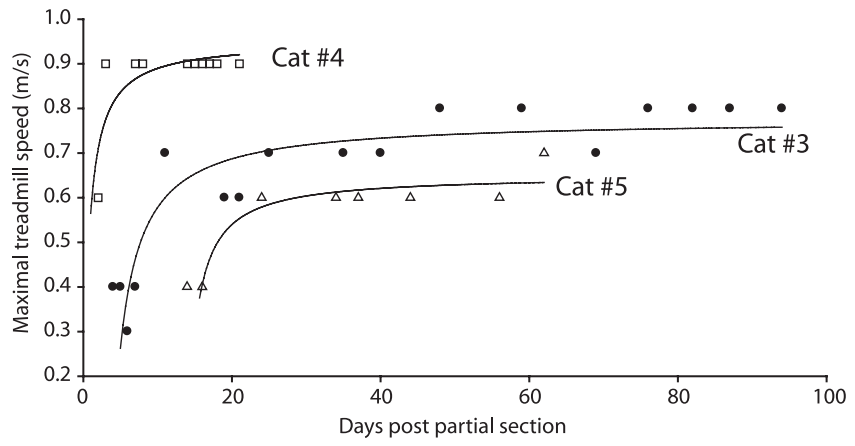

Figure 3. Locomotor performance of trained cats after incomplete spinal section. The maximal speed attained on the treadmill for each trained cat was assessed as a function of days after the partial section.

numerous consecutive steps $(>40)$. In contrast with the first observed episodes of quadrupedal locomotion in this cat, hindlimb locomotor movements on both sides were always achieved with proper plantar foot contact in front of the hip, which can be considered as a good criterion of quality for the recovery. Furthermore, the cat could support its hindquarters and maintain its lateral balance during locomotion without falling on one side or the other for prolonged period of time without assistance.

The time course of the recovery of high treadmill speed quadrupedal locomotion in trained cats is summarized in Figure 3, in which the performance, i.e., the maximal treadmill speed the cats could follow for almost 15-20 steps, is plotted over time after the partial lesion. In cat 4 (small lesion), the recovery process was very quick because, $3 \mathrm{~d}$ after injury, sustained locomotion was achieved up to $0.9 \mathrm{~m} / \mathrm{s}$, at which the animal plateaued up to $21 \mathrm{~d}$ after injury, just before the complete spinalization. In cats 3 and 5, it can be noted that high treadmill stepping $(>0.6 \mathrm{~m} / \mathrm{s})$ was achieved within $\sim 1$ week from the time they began to walk, and then both cats rapidly attained a plateau. Thus, before the complete lesion both cats could walk quadrupedally up to $0.7-0.8 \mathrm{~m} / \mathrm{s}$.

Untrained cats. The absence of training in untrained cats did not prevent quadrupedal locomotor recovery but delayed its reappearance. Because our primary motivation for leaving these cats untrained was to compare their locomotor abilities with those of trained cats after the complete spinal transection (see below), the time course of the recovery after the partial section was not addressed. However, Figure 4 compares a sequence of locomotion $11 \mathrm{~d}$ postpartial section in one untrained (2) and one trained (3) cat that presented similar lesions (Fig. 1C). At the intact state, both cats exhibited a very stable locomotor activity at $0.4 \mathrm{~m} / \mathrm{s}$ as illustrated by the regular successive steps reconstructed from the left hindlimb (Fig. $4 A, B$, top). Eleven days after injury, cat 2 could possibly initiate small episodes of quadrupedal locomotion (no more than 10-15 irregular steps) at very low treadmill speed only $(0.2 \mathrm{~m} / \mathrm{s})$ (Fig. $4 A$ ). During such episodes, a proper hindquarter support was lacking and the cat walked in a more crouched position than in the intact state. This is illustrated by the different levels of the iliac crest during locomotion in the incomplete spinal $(0.2 \mathrm{~m} / \mathrm{s})$ and intact (dotted line, $0.4 \mathrm{~m} / \mathrm{s}$ ) states. The irregular angular excursion of all joints from one cycle to another (bottom) further attest to the poor locomotor capacity in this cat that most of the time exhibited a dorsal foot placement at treadmill contact that remained during stance (see the continuous flexion of the MTP joint during the sequence). In contrast, by this time, trained cat 3 had already regained its ability to regularly step on the treadmill at an even higher speed, with full hindquarter support, and regular excursions at all joints (Fig. $4 B$ ). Similarly, the capacity of untrained cat 1 to perform on the treadmill was evaluated $19 \mathrm{~d}$ after the partial lesion. At this stage, a consistent quadrupedal locomotion was observed at $0.4 \mathrm{~m} / \mathrm{s}$ (data not shown).

\section{Spontaneous motor behaviors and scratching}

It was particularly important to ascertain that voluntary descending control of the sublesional networks remained despite the partial section because it has been reported that occasionally complete spinal cats can express for short period of time an apparently organized quadrupedal locomotion (Ten Cate, 1939; Shurrager and Dykman, 1951; Shimizu, 1991). To evaluate the maintenance of some voluntary control and hence that some descending pathways were still functional, we observed how cats used their hindlimbs in their resting area or in the laboratory. One example of voluntary unrestrained motor behavior is provided in Figure $5 \mathrm{~A}$ for cat 3, $88 \mathrm{~d}$ after the partial section. The continuous hindlimb EMG recordings and associated footfall pattern of the four limbs have been tagged (1-9) to illustrate the cat behavior reconstructed from the video recording (above figurines). It can be seen that from a lying down position (1), the cat could voluntarily straighten up on its forelimb (2), then on both hindlimbs (3), initiate two steps (4), stop (5), turn back to its right (6), make 2 other steps $(7,8)$ and finally sit down $(9)$. This sequence clearly demonstrates that many aspects of the voluntary descending control of the lumbosacral locomotor network were present after the partial lesion. In addition, in two cats ( 3 and 5) the ability to scratch the ears with the hindlimbs in response to gentle brushing was tested. In both cats, scratching activities could be triggered on the right side (contralateral to the lesion) when the right ear was brushed (Fig. $5 B$ ), but could never be induced on the lesioned side (not illustrated) when the left ear was stimulated. This asymmetry probably reflects the fact that this motor behavior requires the integrity of some ipsilateral descending pathways at least from the brainstem down to the spinal cord.

\section{Locomotor recovery after the complete spinal cord section}

The second step of the dual-lesion paradigm consisted of complete spinal cord transection in both trained and untrained cats and then documenting the time course of locomotor recovery (Fig. 1). The complete section of the spinal cord was achieved below the first incomplete section, at T13 (cats 1 to 4) or L1 (cat 5) after which all cats were regularly trained on the treadmill. It should be pointed out that these levels for complete spinalization corresponds to the levels used in earlier studies on spinal cats (Barbeau and Rossignol, 1987; Lovely et al., 1990). In trained cats 3,4 , and 5, the spinalization was done when the locomotor performance had already attained a plateau, 94, 21, and $62 \mathrm{~d}$ after the partial lesion, respectively. In untrained cats, the spinalization was achieved 26 (cat 1) and 55 (cat 2) d after the partial lesion.

\section{Immediate spinal locomotion in trained cats}

One of the major finding was that, as early as $24 \mathrm{~h}$ after spinalization (i.e., the first testing session), all cats that were previously trained in the partial spinal state expressed a bilateral hindlimb pattern of locomotion on the treadmill. Figure 6 illustrates the locomotor pattern observed in cat 4 walking at very high treadmill speed $(0.8 \mathrm{~m} / \mathrm{s})$ while in the intact state $(A)$, incomplete spinal state $(B)(18 \mathrm{~d})$, and complete spinal state $(C)(24 \mathrm{~h})$. In the latter, the recorded hindlimb locomotor electromyograms were already clearly well organized and similar to those recorded in the intact and incomplete spinal states. This included the 
A

\section{Untrained Cat \#2} Intact $-0.4 \mathrm{~m} / \mathrm{s}$

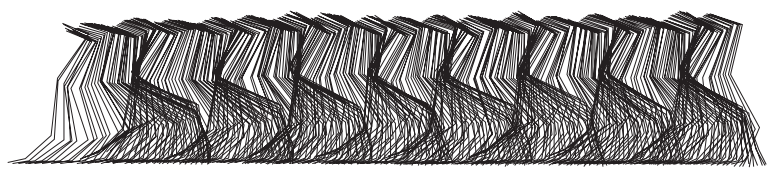

Incomplete spinal $11 \mathrm{~d}-0.2 \mathrm{~m} / \mathrm{s}$

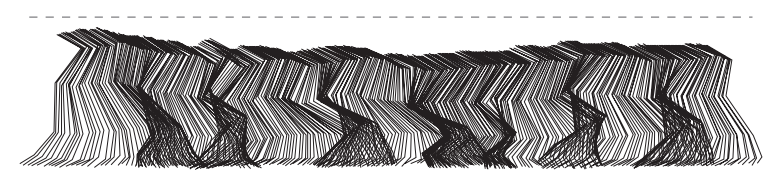

B

\section{Trained Cat \#3 \\ Intact $-0.4 \mathrm{~m} / \mathrm{s}$}

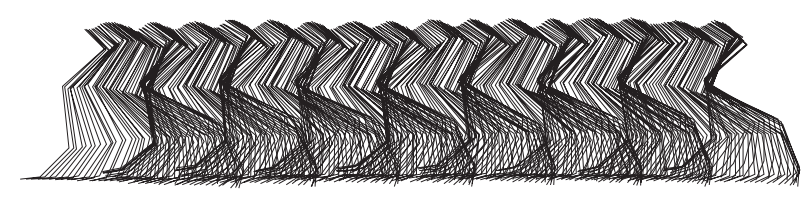

Incomplete spinal $11 \mathrm{~d}-0.4 \mathrm{~m} / \mathrm{s}$

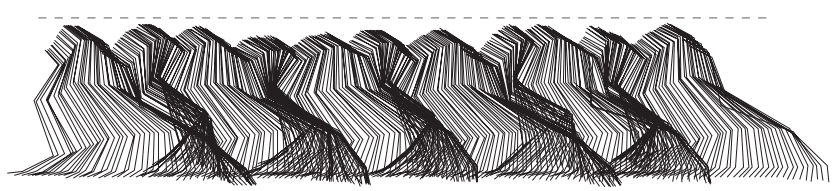

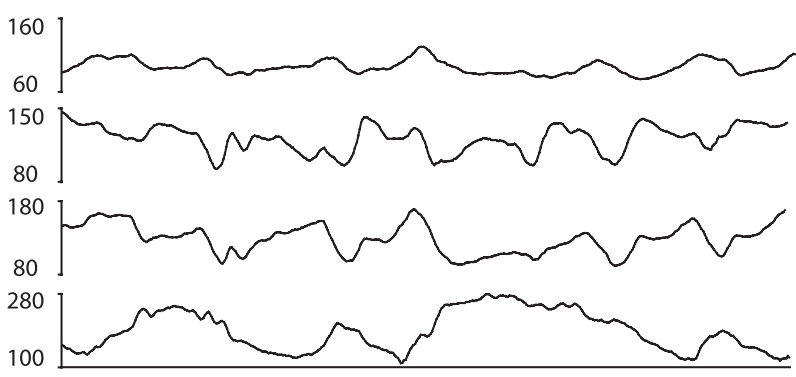

\section{Hip}

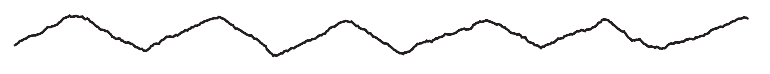

Knee

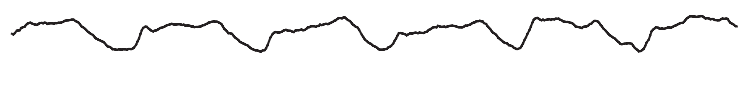

Ankle

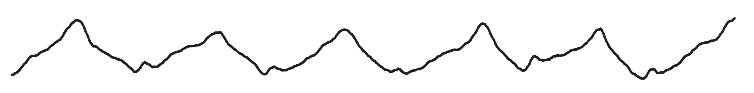

MTP

Figure 4. Treadmill training promotes locomotor recovery after incomplete spinal lesion. $A, B$, Stick figures representing consecutive step cycles of the left hindlimb in the intact state $(0.4 \mathrm{~m} / \mathrm{s})$ and $11 \mathrm{~d}$ after the incomplete spinal lesion in one untrained (2) and one trained (3) cat. The bottom panel shows the corresponding angular excursions of the hip, knee, ankle, and MTP joints $11 \mathrm{~d}$ after the partial section. Note that the untrained cat walked at $0.2 \mathrm{~m} / \mathrm{s} 11 \mathrm{~d}$ after the partial lesion, whereas the trained cat stepped at $0.4 \mathrm{~m} / \mathrm{s}$.

proper left/right and flexor (Srt, St)/extensor (GM, GL) alternating activities. The footfall pattern of the hindlimbs shown below the electromyograms indicates that the normal coupling in phase opposition between both hindlimbs was not only maintained but also stable over time. The kinematics of the hindlimbs in this cat was not significantly affected by the complete lesion as exemplified by the stick diagram reconstructing typical swing and stance phases of the left hindlimb, extracted from the same sequence as the electromyograms. At this very high treadmill speed for spinal locomotion, many if not all the criteria usually used to assess the quality of spinal locomotion were met, including good hindquarter weight support, plantigrade paw placement in front of the hip at stance onset, and little paw drag at the beginning of swing.

The coordination of hindlimbs during episodes of locomotion was measured in the intact state as well as in the incomplete and complete spinal states. In Figure 7, each horizontal bar represents the mean length of the stance (or swing) reconstructed from the mean position of the toes relative to the hip at treadmill contact and elevation (Fig. 7, inset) on both sides (left, black; right, gray) during episodes of locomotion at $0.4 \mathrm{~m} / \mathrm{s}$ over time after the complete spinalization. It can be noted that as early as $24 \mathrm{~h}$ after spinalization, all trained cats (Fig. $7 A-C$ ) exhibited symmetrical locomotor movements on both sides, with paw contact in front of the hip and swing initiation behind the hip joint, that remained over time. A persistent slight decrease in stance (or swing) length over time was however observed when compared with the intact and partial spinal states. Such an early recovery of hindlimb locomotion has never been observed in cats with a complete spinal transection, which are usually incapable of weight-supported treadmill locomotion before weeks of treadmill training (Barbeau and Rossignol, 1987).

Despite the very early spinal locomotion observed in all trained cats, a difference in the ability to initiate and maintain spinal stepping without perineal stimulation on the treadmill was noted between these cats. Perineal stimulation is classically used in the early days after a complete spinalization to increase the excitability of the locomotor network. In cat 4 , episodes of locomotion up to $0.8 \mathrm{~m} / \mathrm{s}$, such as the one presented in Figure $6 C$, could be obtained spontaneously without external stimulation as soon as $24 \mathrm{~h}$ after spinalization. Perineal stimulation, in this case, only increased the locomotor capacities at higher treadmill speed (up to $1.0 \mathrm{~m} / \mathrm{s}$ ) and allowed the maintenance of spinal locomotion for several tens of consecutive steps. In cat 3, however, no organized locomotor movements were obtained without perineal stimulation on the first $2 \mathrm{~d}$ after the lesion, but the stimulation was no more required on the after days. In contrast, hindlimb locomotion in cat 5 showed a prolonged dependency on perineal stimulation and consistent episodes of spontaneous spinal locomotion were obtained 3 weeks after spinalization.

\section{Early asymmetric locomotion in untrained cats}

Untrained cats showed a marked difference in the recovery of spinal locomotion compared with trained cats. The first major difference was that an important asymmetry in stepping capacity between both hindlimbs was observed during the first $10 \mathrm{~d}$ after complete spinalization. A sequence of locomotion illustrating the locomotor pattern $(0.4 \mathrm{~m} / \mathrm{s})$ obtained $5 \mathrm{~d}$ postlesion in untrained cat 2 is presented in Figure 8 B. At the EMG level, some bilateral locomotor activity with left/right alternation and phase opposition between ipsilateral flexors and extensors burst was observed. However, kinematic analyses showed that the right hindlimb did not step at that time, remaining most of the time in a flexed position, and only indirectly (and not proactively) contacted the treadmill because the pelvis fell down during the left swing phase. Consequently, a unilateral spinal locomotion was observed on the left side as illustrated by the duty cycle representation of the 
A Trained cat \#3 - Incomplete spinal $88 \mathrm{~d}$-Voluntary unrestrained motor behavior
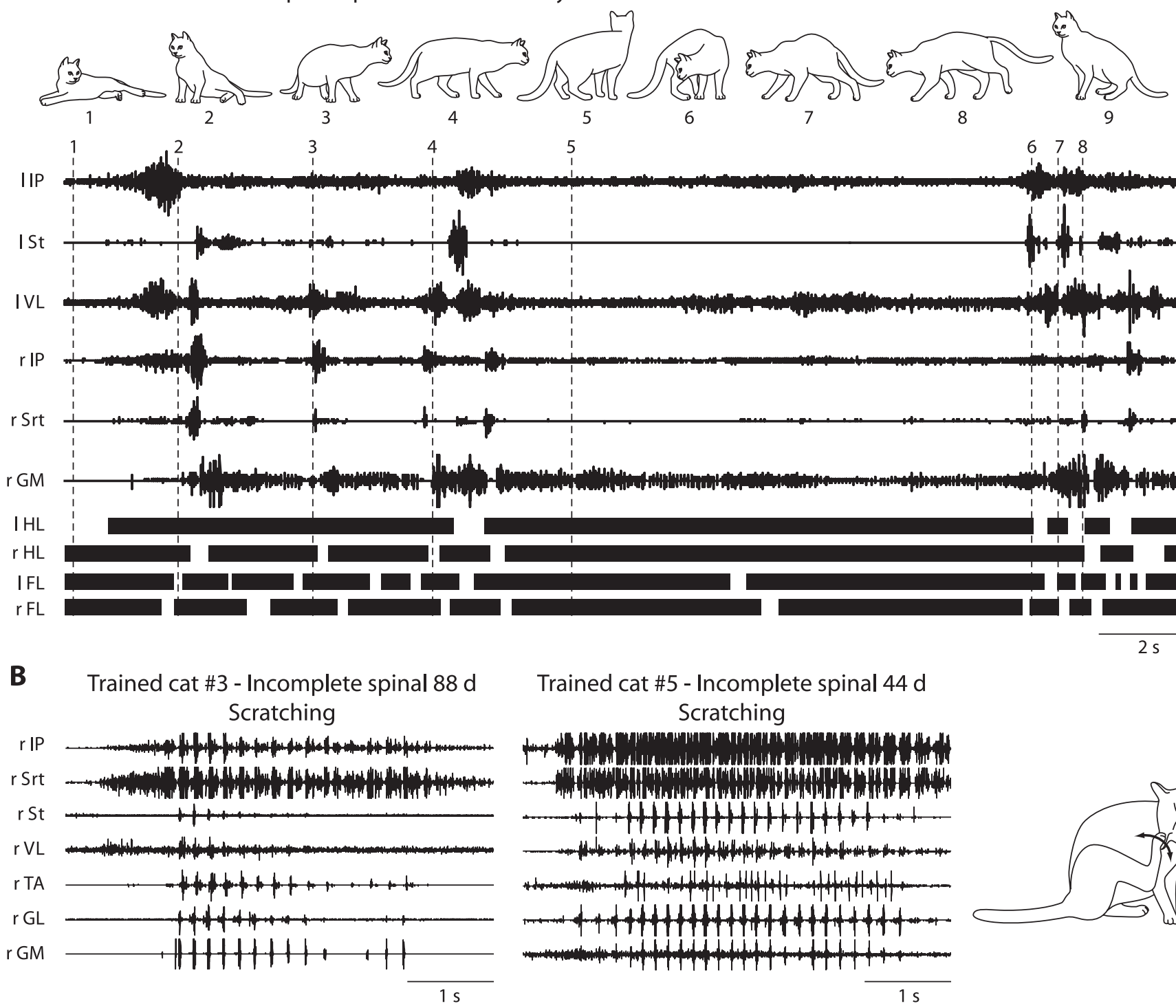

6

7

8

9

678
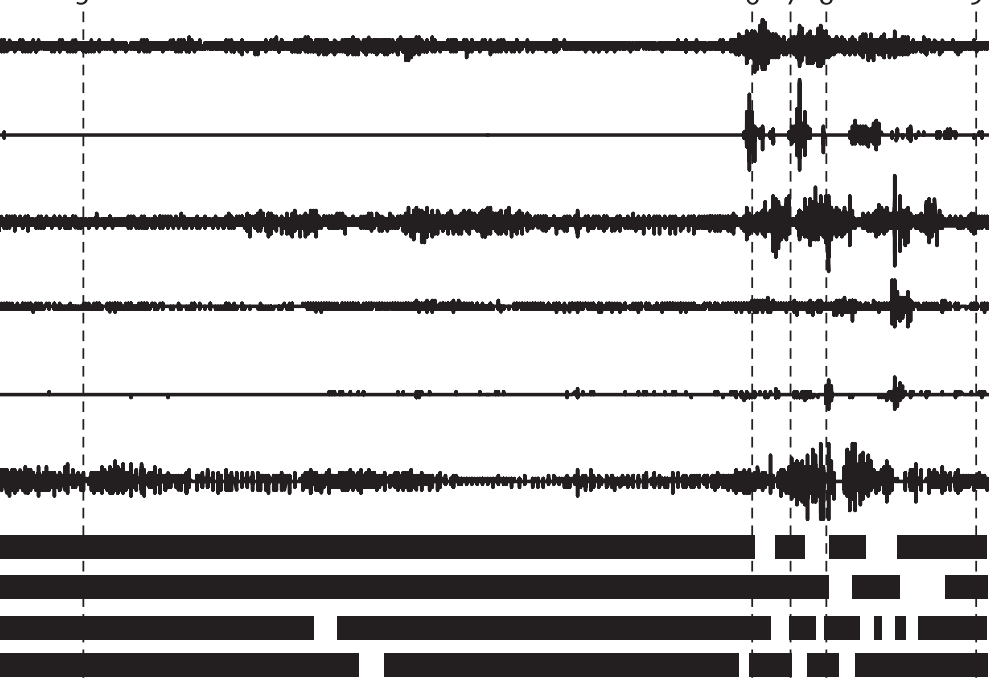

Trained cat \#5 - Incomplete spinal 44 d

$$
\text { Scratching }
$$

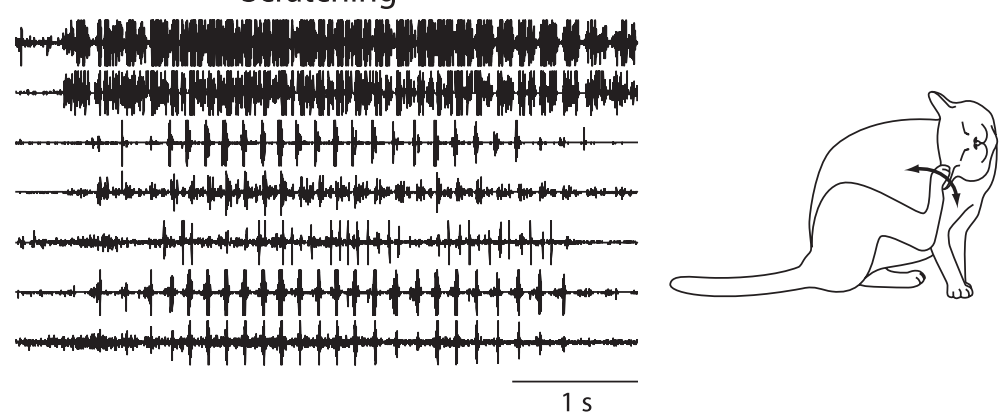

Figure 5. Voluntary motor behavior and scratching in trained cats after the incomplete spinal lesion. $\boldsymbol{A}$, Spontaneous voluntary motor behavior (top) and corresponding EMG activity in cat 3 . Vertical doted lines in the electromyogram indicate the time for each figurine. The four bottom traces show the footfall pattern for each limb. $\boldsymbol{B}$, EMG recordings during scratching of the right leg in cats 3 and 5 at 88 and $44 \mathrm{~d}$ post partial section, respectively. The cat figurine on the far right illustrating the scratching was reconstructed from video recordings of cat 5 .

support phases on both sides below the electromyograms (Fig. $8 B$ ). Locomotion of the left hindlimb (i.e., on the side of the partial section) was well developed and shared many characteristics of normal locomotion. Although there was a paw drag at swing onset, the left hind paw contacted the treadmill in front of the hip with appropriate plantigrade placement. Moreover, the left hindlimb locomotor pattern could be adapted to increasing treadmill speeds $(0.3-0.7 \mathrm{~m} / \mathrm{s})$ for several consecutive steps (Fig. $9 D)$. In contrast with cat 2 , cat 1 demonstrated less stepping capabilities during the early stage $(2-10 \mathrm{~d})$. During that period, only brief episodes of locomotion on the left side, limited to 4-5 consecutive steps were sometimes observed at low treadmill speeds $(0.3 \mathrm{~m} / \mathrm{s})$ (Fig. 9C). Locomotion of the left hindlimb was similar to the one classically observed two to 3 weeks after the beginning of training in "classical" spinal cats. An important paw drag during swing combined with a dorsal paw placement behind the hip at contact was most of the time observed (Fig. 9A). During locomotor episodes, the right hindlimb activity was disorganized and under no circumstances represented a locomotor activity.
In summary, during the first 10-12 d after spinalization, locomotion in cats 1 and 2 was mostly asymmetrical, the capacity of the left hindlimb, i.e., on the side of the primary partial lesion, being considerably better than the right one. Here again, it can be noticed that the early capacity of the left hindlimb to exhibit such locomotor movements in the early days after the complete spinalization contrasts with the delay normally required for the reexpression of spinal stepping (Barbeau and Rossignol, 1987).

Treadmill training improvement of spinal locomotion As shown in the previous sections, in the early days after the complete lesion the major difference between trained and untrained cats (in the partial spinal state) is the expression of a bilateral versus unilateral stepping activity. One important finding was that with additional treadmill training bilateral spinal locomotion emerged within 10-12 d after spinalization (i.e., a normal delay for spinal locomotion) in untrained cats. A sequence of bilateral spinal locomotion at $0.4 \mathrm{~m} / \mathrm{s}$ in untrained cat 2, $18 \mathrm{~d}$ after the spinalization, is illustrated in Figure $8 \mathrm{C}$. After the 
A

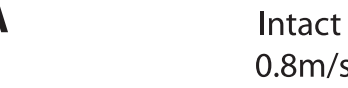

B

B Incomplete spinal $18 \mathrm{~d}$ $0.8 \mathrm{~m} / \mathrm{s}$
C Complete spinal $24 \mathrm{~h}$ $0.8 \mathrm{~m} / \mathrm{s}$
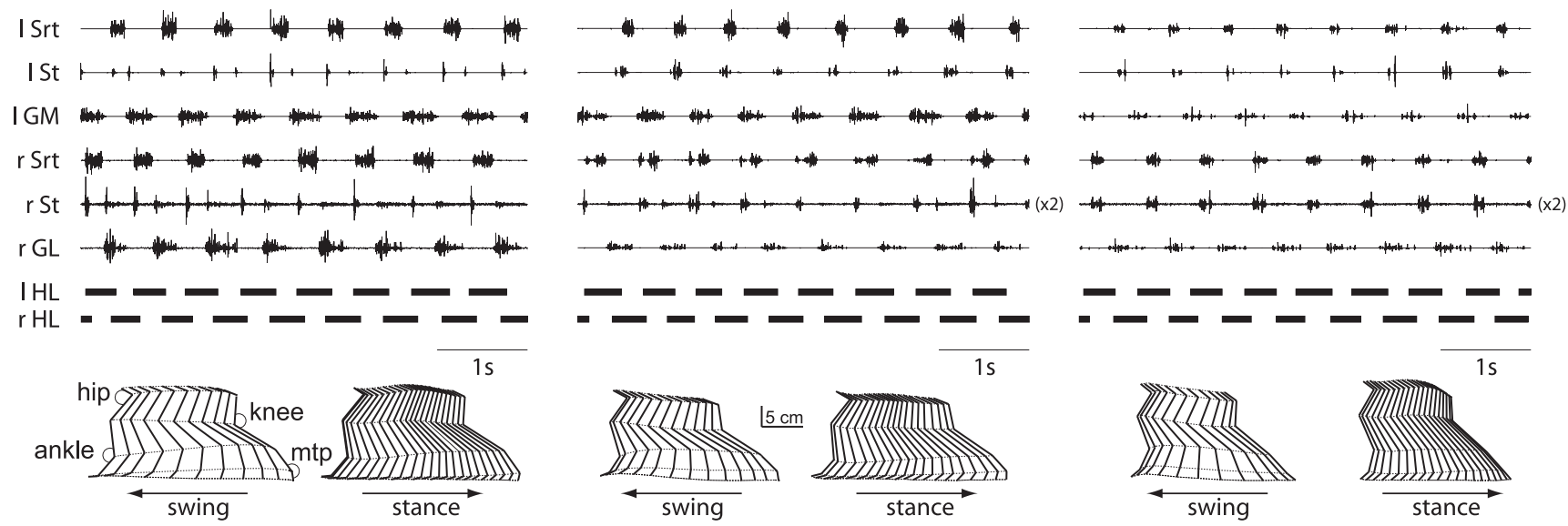

Figure 6. Left limb kinematics and bilateral EMG activity of a trained cat (4) walking at $0.8 \mathrm{~m} / \mathrm{s}$ in the intact, incomplete, and complete spinal states. $A-C$, EMG bursts of selected muscles in the left (I) and right ( $r$ ) hindlimbs (top). The two bottom traces show associated duty cycles of the stance phases for both HLs. The bottom panels show a stick representation of a typical swing and stance phase of the left hindlimb reconstructed from video recordings.

A

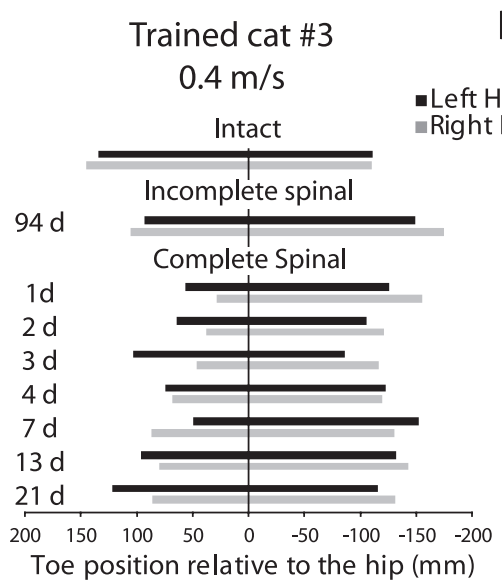

B

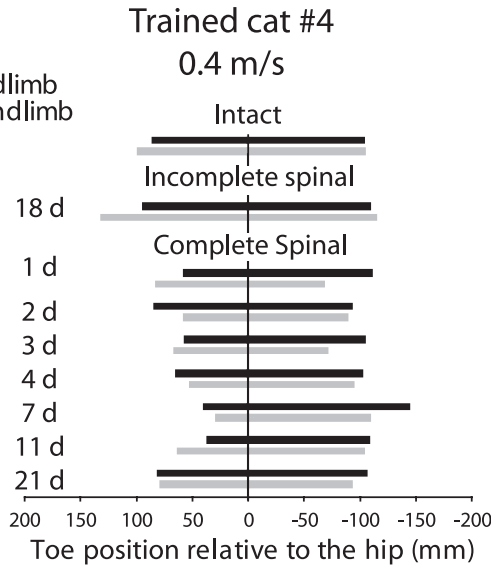

C

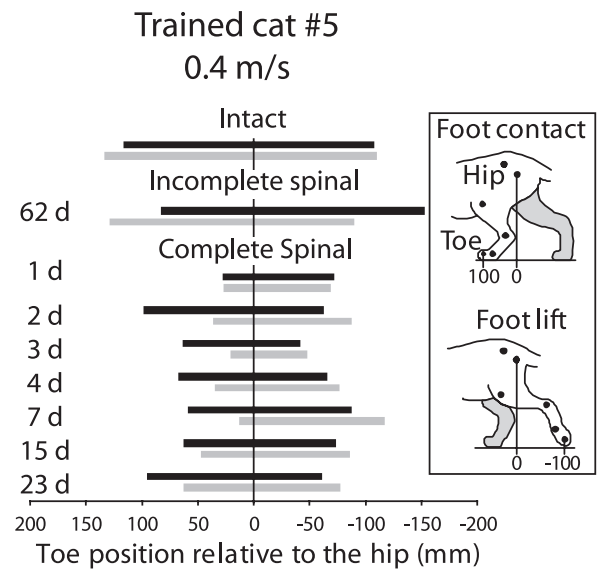

D

Trained cat \#3

PS perineal stimulation

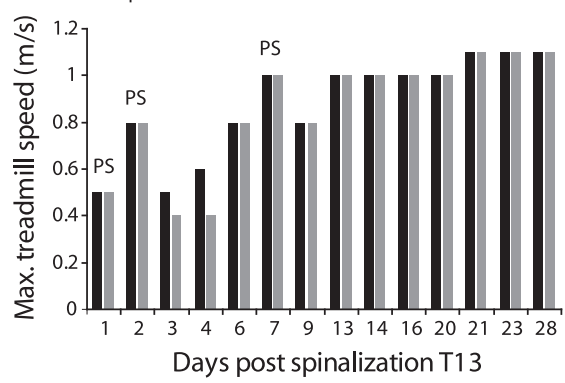

$\mathbf{E}$

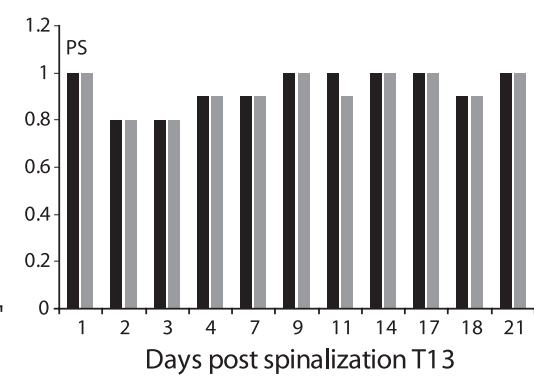

$\mathbf{F}$

Trained cat \#4

Trained cat \#5

Figure 7. Time course of the recovery of hindlimb locomotion in trained cats after complete spinalization. $\boldsymbol{A}-\boldsymbol{C}$, Position of the toes relative to the hip for both hindlimbs at foot contact and lift (see insert on the right) at different epochs during the study in trained cats $3(\boldsymbol{A}), 4(\boldsymbol{B})$, and $5(\boldsymbol{C})$. The left and right extremity for each bar represent the mean position of the toes at foot contact and foot lift, respectively. $\boldsymbol{D}-\boldsymbol{F}$, The maximal speed attained by each limb for each trained cat as a function of time after the complete spinal section. PS, Perineal stimulation.

complete spinalization, the pattern of EMG bursts was well organized resembling the one recorded in the intact state (compare with Fig. $8 A$ ), although slight differences could be noticed. For instance, there was a burst of activity in both Srt, a hip flexor/knee extensor, during stance that was not observed in the intact state. Such an activation of Srt during stance is commonly observed after a complete spinal transection during locomotion on a level surface (Bélanger et al., 1996). In addition the bursting activity of 
A

Intact

$0.4 \mathrm{~m} / \mathrm{s}$
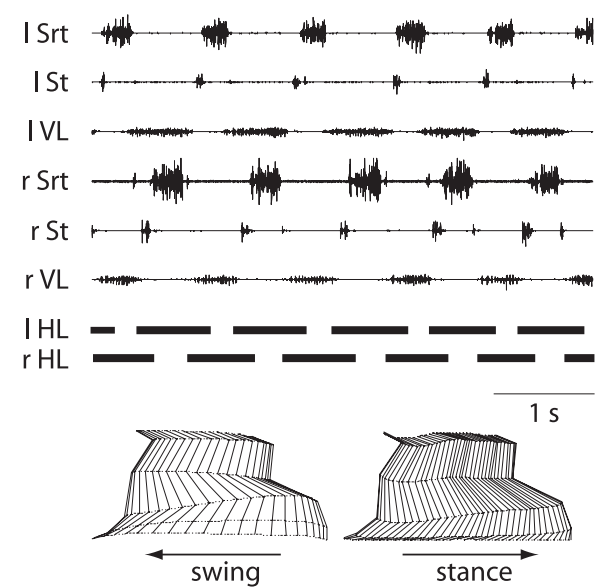

B

Complete spinal $5 \mathrm{~d}$
$0.4 \mathrm{~m} / \mathrm{s}$
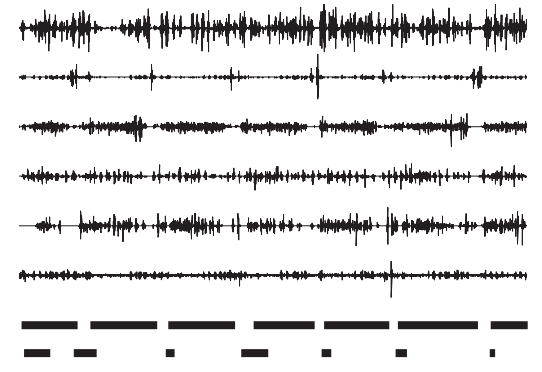

$5 \mathrm{~cm}$
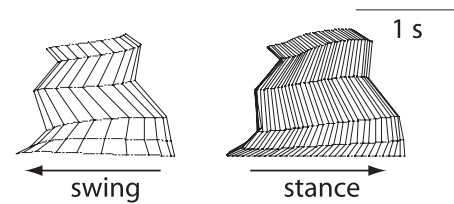

C Complete spinal $18 \mathrm{~d}$ $0.4 \mathrm{~m} / \mathrm{s}$
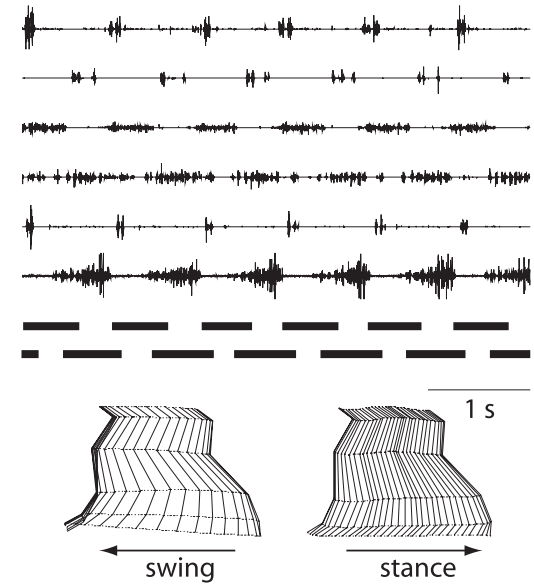

Figure 8. Left hindlimb kinematics and bilateral EMG activity of an untrained cat (2) walking at $0.4 \mathrm{~m} / \mathrm{s}$ in the intact state, at 5 and $18 \mathrm{~d}$ after the complete spinalization. $A-C$, EMG bursts of selected muscles in the left $(I)$ and right $(r)$ hindlimbs (top). The two bottom traces show associated duty cycles of the stance phases for both HLs. The bottom panels give a stick representation of typical swing and stance phases of the left hindlimb reconstructed from video recordings.

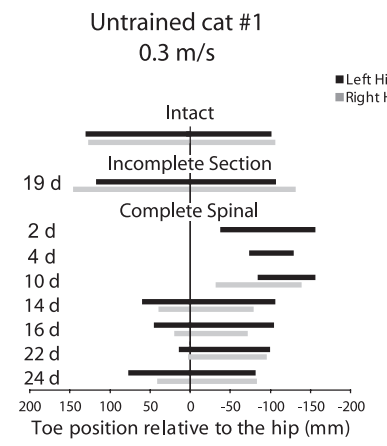

C

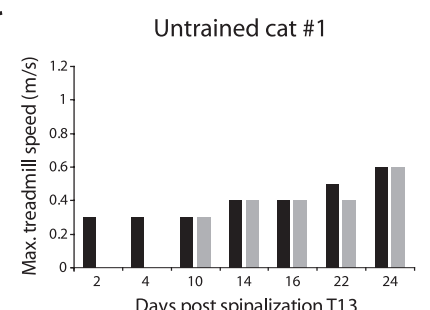

D

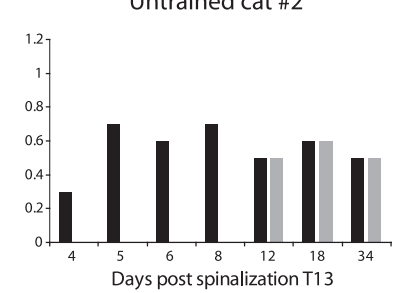

Figure 9. Recovery of hindlimb locomotion after the complete lesion in untrained cats. $A, B$, Diagrams illustrating the toe position relative to the hip of both hindlimbs at contact and lift at different epochs of the complete dual-lesion paradigm, respectively, in untrained cats $1(\boldsymbol{A})$ and $2(\boldsymbol{B}) . \boldsymbol{C}, \boldsymbol{D}$, The maximal speed attained by each limb (performance) for each untrained cat as a function of time after the complete spinal section.

Srt bilaterally was slightly asymmetric, the flexor burst observed in the intact state remained on the right side, but was absent on the left side. Despite this slight asymmetry in the EMG pattern, kinematic analyses showed that the unilateral locomotor activity in the early days after spinalization (Fig. $8 \mathrm{~B}$ ) developed into a bilateral stepping characterized by a proper alternation of support phases on the left and right sides (see duty cycles). This is also illustrated in Figure 9 (top), showing the evolution of the stance (or swing) length relative to the hip position over time after spinalization. After the early recovery of bilateral stepping in untrained cats $1(0.3 \mathrm{~m} / \mathrm{s})$ (Fig. $9 A)$ and $2(0.4 \mathrm{~m} / \mathrm{s})($ Fig. $9 B)$ a symmetrical pattern of hindlimb locomotion was then rapidly reinstated. Bilateral locomotion was then obtained for several consecutive steps with proper plantar paw placements in front of the hip at stance onset.

Finally, another prominent effect of treadmill training after the complete transection was the rapid improvement of the performance in all cats. In trained cats, a rapid capacity of the spinal locomotor pattern to adapt for increasing treadmill speeds was observed (Fig. 7). Despite an initial difference among trained cats on the very first few days after spinalization, these cats regained the ability to perform at very high treadmill speed $(\geq 0.8 \mathrm{~m} / \mathrm{s})$ within 1 week (Fig. $7 D-F$ ). In untrained cats, an improvement in adaptation of spinal locomotion to higher treadmill speed was observed, but was less consistent than in trained animals, the maximal treadmill speed at which spinal locomotion could be obtained ranging from 0.5 to $0.6 \mathrm{~m} / \mathrm{s}$ after 3 weeks of training (Fig. $9 C, D$ ).

\section{Discussion}

In the present work, we provide evidence that marked reorganization of the spinal locomotor network occurred caudal to a partial spinal lesion in the cat. As a result, the reorganized spinal CPG for locomotion may contribute to the recovery of hindlimb stepping during quadrupedal locomotion after partial spinal lesions. In addition, our data suggest that locomotor treadmill training shapes the plasticity of spinal sensorimotor circuits caudal to the partial spinal lesion.

\section{Reorganization of the spinal locomotor network after partial} spinal lesions

The spinal cord contains the necessary circuitry to generate the basic hindlimb locomotor pattern as evidenced from experiments using catecholaminergic stimulation after severing all descending supraspinal inputs (Forssberg and Grillner, 1973; Grillner and Zangger, 1979; Grillner, 1981; Rossignol, 1996). After a complete chronic spinal transection, the spinal locomotor CPG is undoubtedly critical for the expression of locomotion, which must involve appropriate reorganization of the spinal circuitry (Frigon and Rossignol, 2006; Rossignol, 2006). In "normal" cats (i.e., without a previous partial spinal lesion as is the case here), the expression of locomotion after a complete spinalization nor- 
mally takes 2-3 weeks of treadmill training without pharmacological aids (Barbeau and Rossignol, 1987). However, in the present study, bilateral hindlimb locomotion could be expressed as early as $24 \mathrm{~h}$ after a complete spinalization at T13-L1 in cats that had previously recovered a voluntary quadrupedal locomotion after a partial spinal lesion at T10-11 performed some weeks before. One day after the complete spinalization, several criteria used to assess the quality of spinal locomotion in normal chronic spinal cats were already met, including good hindquarter support and proper plantigrade contact in front of the hip.

The very early expression of spinal locomotion in these cats indicates that the spinal locomotor circuitry (CPG and sensory afferents) was already "primed" for spinal locomotion. In other words, after the partial lesion, the excitability of interneuronal circuits, including some implicated in the spinal CPG, was modified, but with time and training plastic changes within the spinal cord permitted recovery of excitability. After complete spinalization the spinal CPG (and sensorimotor pathways) was already in a state that allowed it to operate optimally without descending supraspinal inputs. For example, the pattern of EMG bursts recorded from hindlimb muscles during episodes of spontaneous spinal locomotion on the treadmill in one cat (4) was very similar to the one recorded in the intact and incomplete spinal states (Fig. 6 ), suggesting that the hindlimb locomotor pattern is generated by the same neuronal network in the three conditions. Therefore, the spinal locomotor network not only plays a key role in the recovery of hindlimb locomotion after complete spinalization, but also after partial spinal injuries.

Although, asserting that changes in spinal sensorimotor circuits after incomplete and complete spinal lesions are identical would be very speculative, it is highly likely that some underlying mechanisms are common. For instance, hindlimb locomotion after complete and incomplete spinal lesions is increasingly dependent on the proper integration of sensory afferent inputs (Muir and Steeves, 1995, 1997; Bouyer and Rossignol, 2003) and it has been proposed that a normalization of these inputs is required for the expression of spinal stepping (Cote et al., 2003; Cote and Gossard, 2004). However, changes in neuronal and synaptic properties (Heckmann et al., 2005) and in neuromodulatory systems intrinsic to the spinal cord (de Leon et al., 1999; Giroux et al., 1999, 2003; Chau et al., 2002; Edgerton et al., 1997; Tillakaratne et al., 2002), are undoubtedly also involved.

Despite markedly different partial lesions (Fig. 1), some plastic remodeling of the spinal locomotor network must have occurred because all trained cats expressed a remarkable spinal locomotion on the first day after the complete spinalization. It is likely that remaining descending pathways and the contralateral (i.e., the intact side) half of the spinal cord initiated and shaped the spinal plasticity after the first partial lesion. Indeed, the time course of quadrupedal locomotor recovery and the quality of spinal locomotion after complete transection in trained animals was inversely related to the size of the partial lesion. From previous work, it does not appear that the integrity of specific descending systems is critical for the recovery of locomotion because, despite specific locomotor deficits associated with lesions of specific descending tracts, cats can recover quadrupedal locomotion after different partial lesions (Murray and Goldberger, 1974; Kato et al., 1984; Gorska et al., 1993; Helgren and Goldberger, 1993; Kuhtz-Buschbeck et al., 1996; Jiang and Drew, 1996; Brustein and Rossignol, 1998). Furthermore, although reorganization of pathways originating above the partial spinal lesion (Fouad et al., 2001; Raineteau and Schwab, 2001; Raineteau et al., 2002; Bareyre et al., 2004; Thomas and Gorassini, 2005; Ballermann and Fouad,
2006) is no doubt involved in maintaining a voluntary control of spinal networks (Fig. 5), the primary role of the CPG, that of generating the basic pattern of hindlimb muscle activity during locomotion, is probably not superseded by descending commands. The intact side of the spinal cord probably provides important inputs to the lesioned side via commissural interneurons that receive inputs from the moving hindlimb and from supraspinal pathways (Jankowska, 2008) to drive the spinal plasticity, but this requires additional investigation.

\section{Treadmill training promotes spinal plasticity}

In agreement with previous data in rats and cats (de Leon et al., 1998; Fouad et al., 2000; Gulino et al., 2007), treadmill training was not critical for the re-expression of quadrupedal locomotion after the partial lesions because untrained cats could spontaneously regain the ability to voluntarily walk on the treadmill with all four limbs. However, locomotor training greatly facilitated the recovery of locomotion after the partial spinal lesion (Lovely et al., 1986, 1990; Barbeau and Rossignol, 1987; Bélanger et al., 1988, 1996; Wernig and Muller, 1992; Dietz et al., 1994; de Leon et al., 1998; Van de Crommert et al., 1998; Harkema, 2001; Sullivan et al., 2002; Barbeau and Visintin, 2003; Rossignol, 2006; Plummer et al., 2007). Comparing locomotor abilities in a trained and untrained cat at the same time after the partial lesion showed that treadmill training promoted an earlier recovery of locomotion (Fig. 4). Furthermore, treadmill training over time restored the ability to perform at high treadmill speeds, regardless of lesion extent (Fig. 3).

Importantly, our results strongly suggest that treadmill training acts directly on the spinal locomotor network by shaping the plasticity of sensorimotor circuits after partial lesions because in the first few days after complete spinalization, trained cats expressed a bilateral spinal stepping whereas untrained cats displayed a unilateral pattern of locomotion on the side of the partial lesion (left). This functional asymmetry after the complete spinalization probably reflected asymmetric changes in spinal circuits bilaterally in the partial spinal state, which by removing descending inputs to the intact side were highlighted (Wolpaw and Lee, 1989; Wolpaw and Tennissen, 2001). Anatomical and functional asymmetric changes taking place in the spinal cord after partial lesions have been reported previously (Murray and Goldberger, 1974; Hultborn and Malmsten, 1983a,b; Helgren and Goldberger, 1993) and we propose that locomotor training, although increasing the amount of locomotor movements (de Leon et al., 1998; Rossignol et al., 2004; Cha et al., 2007), directly influences functional reorganization of the spinal circuitry bilaterally. It should be noted that, the untrained cat that was kept in the partial spinal state for the longest period of time (cat 2) showed better organized unilateral stepping after complete spinalization probably because it had more time to move around its cage, which represents a form of self-training.

Interestingly, with additional treadmill training after the complete transection, a bilateral and symmetrical spinal locomotion in untrained cats was reinstated demonstrating that plasticity can still occur after the complete spinal lesion (Bouyer and Rossignol, 2003). Possible mechanisms subserving the permissive action of treadmill training in the re-expression of hindlimb locomotion remain mostly unknown despite recent progress (de Leon et al., 1999; Tillakaratne et al., 2002; Cote et al., 2003; Cote and Gossard, 2004; Ying et al., 2005). The present work provides functional evidence that treadmill training shapes spinal plasticity after partial lesions. 


\section{Conclusion}

From our experiments, several conclusions can be drawn in the context of locomotor recovery after spinal lesions. First, the recovery of quadrupedal locomotion after partial lesions is mostly the result of an intrinsic reorganization of the spinal locomotor network below the lesion. Second, locomotor training is a major factor in facilitating the recovery process because cats intensively trained after the partial lesion expressed a very high locomotor performance bilaterally within hours of the complete spinalization, whereas in untrained animals only a unilateral locomotion was observed in the limb ipsilateral to the partial lesion. Third, plastic reorganization of the spinal CPG may still occur after the complete spinal section because bilateral locomotor performance improved with training over time in all cats after complete spinalization. Altogether, the present work highlights the importance of promoting spinal neuroplasticity in rehabilitation strategies in SCI patients, especially to maintain the spinal circuitry in an optimal condition to generate locomotion.

\section{References}

Ballermann M, Fouad K (2006) Spontaneous locomotor recovery in spinal cord injured rats is accompanied by anatomical plasticity of reticulospinal fibers. Eur J Neurosci 23:1988-1996.

Barbeau H, Rossignol S (1987) Recovery of locomotion after chronic spinalization in the adult cat. Brain Res 412:84-95.

Barbeau H, Rossignol S (1994) Enhancement of locomotor recovery following spinal cord injury. Curr Opin Neurol 7:517-524.

Barbeau H, Visintin M (2003) Optimal outcomes obtained with bodyweight support combined with treadmill training in stroke subjects. Arch Phys Med Rehabil 84:1458-1465.

Bareyre FM, Kerschensteiner M, Raineteau O, Mettenleiter TC, Weinmann O, Schwab ME (2004) The injured spinal cord spontaneously forms a new intraspinal circuit in adult rats. Nat Neurosci 7:269-277.

Bélanger M, Drew T, Rossignol S (1988) Spinal locomotion: a comparison of the kinematics and the electromyographic activity in the same animal before and after spinalization. Acta Biol Hungarica 39:151-154.

Bélanger M, Drew T, Provencher J, Rossignol S (1996) A comparison of treadmill locomotion in adult cats before and after spinal transection. J Neurophysiol 76:471-491.

Bouyer LJ, Rossignol S (2003) Contribution of cutaneous inputs from the hindpaw to the control of locomotion: 2. Spinal cats. J Neurophysiol 90:3640-3653.

Brustein E, Rossignol S (1998) Recovery of locomotion after ventral and ventrolateral spinal lesions in the cat. I. Deficits and adaptive mechanisms. J Neurophysiol 80:1245-1267.

Cha J, Heng C, Reinkensmeyer DJ, Roy RR, Edgerton VR, de Leon RD (2007) Locomotor ability in spinal rats is dependent on the amount of activity imposed on the hindlimbs during treadmill training. J Neurotrauma 24:1000-1012.

Chau C, Giroux N, Barbeau H, Jordan LM, Rossignol S (2002) Effects of intrathecal glutamatergic drugs on locomotion. I. NMDA in short-term spinal cats. J Neurophysiol 88:3032-3045.

Cote MP, Gossard JP (2004) Step training-dependent plasticity in spinal cutaneous pathways. J Neurosci 24:11317-11327.

Cote MP, Menard A, Gossard JP (2003) Spinal cats on the treadmill: changes in load pathways. J Neurosci 23:2789-2796.

de Leon RD, Hodgson JA, Roy RR, Edgerton VR (1998) Locomotor capacity attributable to step training versus spontaneous recovery after spinalization in adult cats. J Neurophysiol 79:1329-1340.

de Leon RD, Tamaki H, Hodgson JA, Roy RR, Edgerton VR (1999) Hindlimb locomotor and postural training modulates glycinergic inhibition in the spinal cord of the adult spinal cat. J Neurophysiol 82:359-369.

Dietz V, Colombo G, Jensen L (1994) Locomotor activity in spinal man. Lancet 344:1260-1263.

Edgerton VR, de Leon RD, Tillakaratne N, Recktenwald MR, Hodgson JA, Roy RR (1997) Use-dependent plasticity in spinal stepping and standing. Adv Neurol 72:233-247.

Forssberg H, Grillner S (1973) The locomotion of the acute spinal cat injected with clonidine i.v. Brain Res 50:184-186.

Forssberg H, Grillner S, Halbertsma J (1980a) The locomotion of the low spinal cat. I. Coordination within a hindlimb. Acta Physiol Scand 108:269-281.

Forssberg H, Grillner S, Halbertsma J, Rossignol S (1980b) The locomotion of the low spinal cat: II. Interlimb coordination. Acta Physiol Scand 108:283-295.

Fouad K, Metz GA, Merkler D, Dietz V, Schwab ME (2000) Treadmill training in incomplete spinal cord injured rats. Behav Brain Res 115:107-113.

Fouad K, Pedersen V, Schwab ME, Brosamle C (2001) Cervical sprouting of corticospinal fibers after thoracic spinal cord injury accompanies shifts in evoked motor responses. Curr Biol 11:1766-1770.

Frigon A, Rossignol S (2006) Functional plasticity following spinal cord lesions. Prog Brain Res 157:231-260.

Giroux N, Chau C, Barbeau H, Reader TA, Rossignol S (2003) Effects of intrathecal glutamatergic drugs on locomotion. II. NMDA and AP-5 in intact and late spinal cats. J Neurophysiol 90:1027-1045.

Giroux N, Rossignol S, Reader TA (1999) Autoradiographic study of $\alpha_{1^{-}}$, $\alpha_{2}$-noradrenergic and serotonin $1 \mathrm{~A}$ receptors in the spinal cord of normal and chronically transected cats. J Comp Neurol 406:402-414.

Gorska T, Bem T, Majczynski H, Zmyslowski W (1993) Unrestrained walking in cats with partial spinal lesions. Brain Res Bull 32:241-249.

Grillner S (1973) Locomotion in the spinal cat. In: Control of posture and locomotion (Stein RB, Pearson KG, Smith RS, Redford JB, eds), pp 515535. New York: Plenum.

Grillner S (1981) Control of locomotion in bipeds, tetrapods, and fish. In: Handbook of physiology. The nervous system, Vol II (Brookhart JM, Mountcastle VB, eds), pp 1179-1236. Bethesda, MD: American Physiological Society.

Grillner S, Zangger P (1979) On the central generation of locomotion in the low spinal cat. Exp Brain Res 34:241-261.

Gulino R, Dimartino M, Casabona A, Lombardo SA, Perciavalle V (2007) Synaptic plasticity modulates the spontaneous recovery of locomotion after spinal cord hemisection. Neurosci Res 57:148-156.

Harkema SJ (2001) Neural plasticity after human spinal cord injury: application of locomotor training to the rehabilitation of walking. Neuroscientist 7:455-468.

Heckmann CJ, Gorassini MA, Bennett DJ (2005) Persistent inward currents in motoneuron dendrites: implications for motor output. Muscle Nerve 31:135-156.

Helgren ME, Goldberger ME (1993) The recovery of postural reflexes and locomotion following low thoracic hemisection in adult cats involves compensation by undamaged primary afferent pathways. Exp Neurol 123:17-34.

Hultborn H, Malmsten J (1983a) Changes in segmental reflexes following chronic spinal cord hemisection in the cat. I. Increased monosynaptic and polysynaptic ventral root discharges. Acta Physiol Scand 119:405-422.

Hultborn H, Malmsten J (1983b) Changes in segmental reflexes following chronic spinal cord hemisection in the cat. II. Conditioned monosynaptic test reflexes. Acta Physiol Scand 119:423-433.

Jankowska E (2008) Spinal interneuronal networks in the cat: elementary components. Brain Res Rev 57:46-55.

Jiang W, Drew T (1996) Effects of bilateral lesions of the dorsolateral funiculi and dorsal columns at the level of the low thoracic spinal cord on the control of locomotion in the adult cat. I. Treadmill walking. J Neurophysiol 76:849-866.

Kato M, Murakami S, Yasuda K, Hirayama H (1984) Disruption of fore-and hindlimb coordination during overground locomotion in cats with bilateral serial hemisection of the spinal cord. Neurosci Res 2:27-47.

Kuhtz-Buschbeck JP, Boczek-Funcke A, Mautes A, Nacimiento W, Weinhardt C (1996) Recovery of locomotion after spinal cord hemisection: an X-ray study of the cat hindlimb. Exp Neurol 137:212-224.

Lovely RG, Gregor RJ, Roy RR, Edgerton VR (1986) Effects of training on the recovery of full-weight-bearing stepping in the adult spinal cat. Exp Neurol 92:421-435.

Lovely RG, Gregor RJ, Roy RR, Edgerton VR (1990) Weight-bearing hindlimb stepping in treadmill-exercised adult spinal cat. Brain Res 514:206-218.

Muir GD, Steeves JD (1995) Phasic cutaneous input facilitates locomotor recovery after incomplete spinal injury in the chick. J Neurophysiol 74:358-368.

Muir GD, Steeves JD (1997) Sensorimotor stimulation to improve locomotor recovery after spinal cord injury. Trends Neurosci 20:72-77.

Murray M, Goldberger ME (1974) Restitution of function and collateral 
sprouting in the cat spinal cord: the partially hemisected animal. J Comp Neurol 158:19-36.

Nudo RJ (2006) Plasticity. NeuroRx 3:420-427.

Plummer P, Behrman AL, Duncan PW, Spigel P, Saracino D, Martin J, Fox E, Thigpen M, Kautz SA (2007) Effects of stroke severity and training duration on locomotor recovery after stroke: a pilot study. Neurorehabil Neural Repair 21:137-151.

Raineteau O, Schwab ME (2001) Plasticity of motor systems after incomplete spinal cord injury. Nat Rev Neurosci 2:263-273.

Raineteau O, Fouad K, Bareyre FM, Schwab ME (2002) Reorganization of descending motor tracts in the rat spinal cord. Eur J Neurosci 16:1761-1771.

Rossignol S (1996) Neural control of stereotypic limb movements. In: Handbook of physiology, Sec 12, Exercise: regulation and integration of multiple systems (Rowell LB, Sheperd JT, eds), pp 173-216. New York: Oxford UP.

Rossignol S (2006) Plasticity of connections underlying locomotor recovery after central and/or peripheral lesions in the adult mammals. Phil Trans R Soc B 361:1647-1671.

Rossignol S, Drew T, Brustein E, Jiang W (1999) Locomotor performance and adaptation after partial or complete spinal cord lesions in the cat. Prog Brain Res 123:349-365.

Rossignol S, Bouyer L, Langlet C, Barthélemy D, Chau C, Giroux N, Brustein E, Marcoux J, Leblond H, Reader TA (2004) Determinants of locomotor recovery after spinal injury in the cat. Prog Brain Res 143:163-172.

Rossignol S, Dubuc R, Gossard JP (2006) Dynamic sensorimotor interactions in locomotion. Physiol Rev 86:89-154.

Shimizu Y (1991) Locomotive movements of the hindlimbs after complete transection of the spinal cord in adult dogs. In: Neurobiological basis of human locomotion (Shimamura M, Grillner S, Edgerton VR, eds), pp 387-394. Tokyo: Japan Scientific Societies.

Shurrager PS, Dykman RA (1951) Walking spinal carnivores. J Comp Physiol Psychol 44:252-262.

Sullivan KJ, Knowlton BJ, Dobkin BH (2002) Step training with body weight support: effect of treadmill speed and practice paradigms on poststroke locomotor recovery. Arch Phys Med Rehabil 83:683-691.

Ten Cate J (1939) Quelques observations sur la locomotion des chiens dont la moelle épinière est sectionnée transversalement. Arch Neerl Physiol 24:476-485.

Thomas SL, Gorassini MA (2005) Increases in corticospinal tract function by treadmill training after incomplete spinal cord injury. J Neurophysiol 94:2844-2855.

Tillakaratne NJ, de Leon RD, Hoang TX, Roy RR, Edgerton VR, Tobin AJ (2002) Use-dependent modulation of inhibitory capacity in the feline lumbar spinal cord. J Neurosci 22:3130-3143.

Van de Crommert HW, Mulder T, Duysens J (1998) Neural control of locomotion: sensory control of the central pattern generator and its relation to treadmill training. Gait Posture 7:251-263.

Wernig A, Muller S (1992) Laufband locomotion with body weight support improved walking in persons with severe spinal cord injuries. Paraplegia 30:229-238.

Wolpaw JR, Lee CL (1989) Memory traces in primate spinal cord produced by operant conditioning of H-reflex. J Neurophysiol 61:563-572.

Wolpaw JR, Tennissen AM (2001) Activity-dependent spinal cord plasticity in health and disease. Annu Rev Neurosci 24:807-843.

Ying Z, Roy RR, Edgerton VR, Gomez-Pinilla F (2005) Exercise restores levels of neurotrophins and synaptic plasticity following spinal cord injury. Exp Neurol 193:411-419. 